Please do not remove this page

RMIT

UNIVERSITY

\title{
Fabrication and anisotropic wettability of titanium-coated microgrooves
}

Gui, Na; Xu, Wei; Tian, Jie; Rosengarten, Gary; Brandt, Milan; Qian, Ma

https://researchrepository.rmit.edu.au/esploro/outputs/9921859011401341/filesAndLinks?institution=61 RMIT_INST\&index=null

Gui, N., Xu, W., Tian, J., Rosengarten, G., Brandt, M., \& Qian, M. (2018). Fabrication and anisotropic wettability of titanium-coated microgrooves. Journal of Applied Physics, 123(9), 1-8.

https://doi.org/10.1063/1.5020517

Document Version: Published Version

Published Version: https://doi.org/10.1063/1.5020517

Repository homepage: https://researchrepository.rmit.edu.au

(C) 2018 Author(s).

Downloaded On 2023/04/26 21:38:14 +1000

Please do not remove this page 
Thank you for downloading this document from the RMIT Research Repository.

The RMIT Research Repository is an open access database showcasing the research outputs of RMIT University researchers.

RMIT Research Repository: http://researchbank.rmit.edu.au/

\section{Citation:}

Gui, N, Xu, W, Tian, J, Rosengarten, G, Brandt, M and Qian, M 2018, 'Fabrication and anisotropic wettability of titanium-coated microgrooves', Journal of Applied Physics, vol. 123, no. 9, pp. 1-8.

See this record in the RMIT Research Repository at:

https://researchbank.rmit.edu.au/view/rmit:47027

Version: Published Version

Copyright Statement:

(C) 2018 Author(s).

\section{Link to Published Version:}

https://researchbank.rmit.edu.au/view/rmit:47027 


\section{Fabrication and anisotropic wettability of titanium-coated microgrooves}

N. Gui, W. Xu, J. Tian, G. Rosengarten, M. Brandt, and M. Qian

Citation: Journal of Applied Physics 123, 095306 (2018); doi: 10.1063/1.5020517

View online: https://doi.org/10.1063/1.5020517

View Table of Contents: http://aip.scitation.org/toc/jap/123/9

Published by the American Institute of Physics

\section{Scilight}

Sharp, quick summaries illuminating the latest physics research 


\title{
Fabrication and anisotropic wettability of titanium-coated microgrooves
}

\author{
N. Gui, ${ }^{1}$ W. Xu, ${ }^{1,2}$ J. Tian, ${ }^{3}$ G. Rosengarten, ${ }^{4}$ M. Brandt, ${ }^{1}$ and M. Qian ${ }^{1, a)}$ \\ ${ }^{1}$ Centre for Additive Manufacturing, School of Engineering, RMIT University, Melbourne, Victoria 3000, \\ Australia \\ ${ }^{2}$ School of Engineering, Macquarie University, Sydney, New South Wales 2109, Australia \\ ${ }^{3}$ Micro Nano Research Facility, RMIT University, Melbourne, Victoria 3000, Australia \\ ${ }^{4}$ School of Engineering, RMIT University, Melbourne, Victoria 3000, Australia
}

(Received 22 December 2017; accepted 17 February 2018; published online 7 March 2018)

\begin{abstract}
Surface wettability plays a critical role in a variety of key areas including orthopaedic implants and chemical engineering. Anisotropy in wettability can arise from surface grooves, which are of particular relevance to orthopaedic implants because they can mimic collagen fibrils that are the basic components of the extracellular matrix. Titanium (Ti) and its alloys have been widely used for orthopaedic and dental implant applications. This study is concerned with the fabrication of Ticoated microgrooves with different groove widths and the characterisation of the anisotropy in wettability through measuring water contact angles, compared with both the Wenzel and Cassie models. Experimental results revealed that there existed significant anisotropy in the wettability of Ti-coated microgrooves, and the degree of anisotropy $(\Delta \theta)$ increased with an increasing groove width from $5 \mu \mathrm{m}$ to $20 \mu \mathrm{m}$. On average, the contact angle measured parallel to the groove direction $\left(\theta_{/ /}\right)$was about $50^{\circ}-60^{\circ}$ smaller than that measured perpendicular to the groove direction $\left(\theta_{\perp}\right)$. In general, the Wenzel model predicted the contact angles along the surface groove direction reasonably, and so did the Cassie model for the contact angles perpendicular to the groove direction. Osteoblast spreading was affected by the anisotropy in wettability, which occurred preferably along, rather than perpendicular to, the groove direction. These findings are informative for the design of Ti implant surfaces when anisotropy in wettability matters. Published by AIP Publishing.

https://doi.org/10.1063/1.5020517
\end{abstract}

\section{INTRODUCTION}

Titanium (Ti) and its alloys exhibit high strength-toweight ratio, high fracture toughness, excellent corrosion resistance, outstanding biocompatibility and good fatigue properties. ${ }^{1}$ Consequently, they have found critical applications in a wide variety of sectors including chemical engineering, pharmaceutical manufacturing, marine and deep sea engineering, filtration of various types of liquid-solid mixtures, orthopaedic implants, etc. ${ }^{2}$ In most of these applications, the surfaces of $\mathrm{Ti}$ components or devices are kept in contact with a liquid, where wettability is important for the anticipated functionality. Typical examples include open porous Ti used as corrosion-resistant filters and bone implants for enhanced osseointegration. ${ }^{2}$

A number of studies have shown that surface topography, especially patterned grooves, can noticeably affect the wettability of a solid surface including the isotropy of wettability. ${ }^{3-5}$ One area of particular interest is the surface design of orthopaedic implants. Wettability can play a critical role in cell responses to microgrooved Ti substrates. ${ }^{6}$ Grooves on such implant surfaces are capable of, e.g., mimicking collagen fibrils that are the basic components of the cell living environment, namely the extracellular matrix $(\mathrm{ECM}){ }^{7}$ Ding et al. have demonstrated that cells behaved similarly to viscous liquids in the initial stage of spreading on grooved surfaces, ${ }^{8}$ with their semimajor axis closely aligned with the groove direction. This observation suggests that further

${ }^{\text {a)} E l e c t r o n i c ~ m a i l: ~ m a . q i a n @ r m i t . e d u . a u ~}$ scrutinizing anisotropic wettability of a liquid can improve our understanding of cell response to grooved surfaces.

In principle, surface wettability can be tuned by changing either surface chemistry ${ }^{9}$ or surface topography ${ }^{10}$ or a combination of both approaches. ${ }^{11}$ For instance, the chemical treatment such as plasma treatment of $\mathrm{CHF}_{3}, \mathrm{CF}_{4}$ or $\mathrm{O}_{2}$ via reactive ion etching (RIE) can modulate the anisotropic wettability of surfaces with submicron-scaled grooves. ${ }^{9}$ On the other hand, anisotropic wettability can also be manipulated via changing the aspect ratio of groove patterns (i.e., the groove depth-to-width ratio). ${ }^{12}$ It requires no additional chemical treatments, thereby avoiding the introduction of surface contamination. ${ }^{12}$ With regard to Ti surfaces, it has been shown that enhancing surface wettability by simultaneously altering the surface chemistry and surface topography can promote in vitro osteoblast (bone-forming cell) responses. ${ }^{6}$ Owing to the anisotropy in groove geometry, cells generally elongate and align along the groove direction, ${ }^{13}$ as illustrated in Fig. 1. As this is an area that is still not fully understood, here, we aim to further unravel the underlying correlation between the anisotropic wettability and the grooved patterns, particularly the dependency of anisotropic wettability on the groove width, the aspect ratio and the space ratio.

\section{PATTERN DESIGN AND BASIC THEORETICAL MODELS FOR WETTING A GROOVED SURFACE}

Figure 2 shows a schematic drawing of the designed surface microgrooves with the ridge width denoted as $a$, the groove width as $b$ and the depth as $d$. Changing one of these 


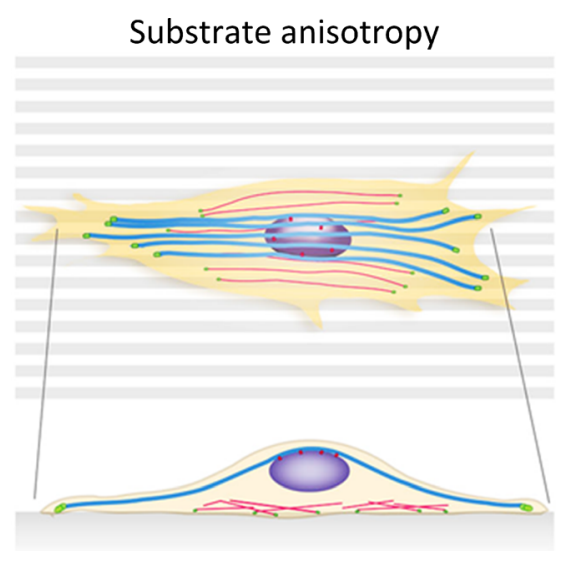

Bird view

Side view

FIG. 1. Illustration of cell responses to substrate anisotropy. When cells are cultured on surface grooves, the cells tend to align along the groove direction. Focal adhesions are protein assemblies, which are essential in regulating cell responses and a few microns in size (green). Basal actin fibres (pink) and actin cap fibres (blue) also align along the groove direction. The side view (bottom) illustrates the arrangement of actin cap fibres and basal actin fibres. Reproduced with permission from Tamiello et al., Cell. Mol. Bioeng. 9(1), 12 (2016). Copyright 2016, licensed under Creative Commons Attribution 4.0 International License (http://creativecommons.org/licenses/by/4.0).

groove features can potentially influence surface wettability. As pointed out earlier, this study is particularly interested in enhancing osteoblast responses. Considering the compatibility of grooved patterns with osteoblasts, here, a series of groove widths in the range of $5 \mu \mathrm{m}$ to $20 \mu \mathrm{m}$ were selected because the average size of a typical osteoblast is about 20-30 $\mu \mathrm{m}$ (Ref. 14), and more pronounced cell responses are triggered when groove widths are comparable with cell size. ${ }^{15}$ The minimum groove width is chosen to be $5 \mu \mathrm{m}$ in relation to the typical osteoblast size of $20-30 \mu \mathrm{m}$ because narrower grooves risk developing significant incomplete contact with osteoblasts. ${ }^{16}$ The groove depth of $2 \mu \mathrm{m}$ was selected based on two findings. One is that grooves of $2 \mu \mathrm{m}$ deep can stimulate the expression of osteogenic markers (i.e., the markers of osteogenic capacity for a bone implant surface) to a greater extent than shallower grooves $(35 \mathrm{~nm}$ and $306 \mathrm{~nm}){ }^{17}$ The other is that they can induce more significant cell elongation than deeper grooves (e.g., $4.8 \mu \mathrm{m}){ }^{18}$ This suggests that, in general, $2 \mu \mathrm{m}$-deep grooves are appropriate to exert contact guidance for cells. ${ }^{18}$

Ridge width is another parameter of the grooved surface topography. It is fixed at $5 \mu \mathrm{m}$, in relation again to the osteoblast size of $20-30 \mu \mathrm{m}$ to avoid turning them into sharp edges for osteoblasts, where groove edges can hinder the migration of a liquid or viscous object. ${ }^{3,19}$ Table I lists the detailed dimensions of the designed microgrooves. The aspect ratio

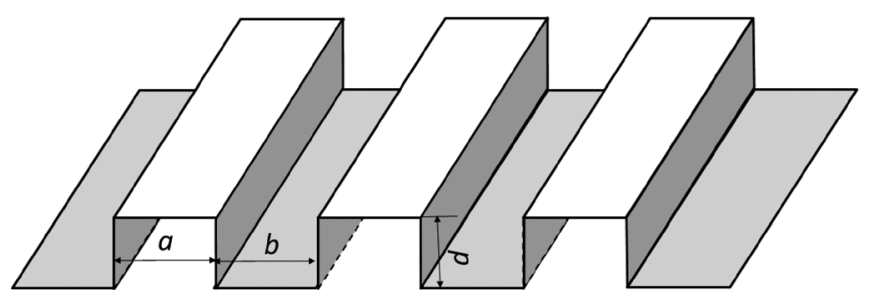

FIG. 2. Schematic drawing of microgrooves on a surface: $a$ : ridge width, $b$ : groove width, and $d$ : groove depth.
TABLE I. Dimensions of designed surface microgrooves.

\begin{tabular}{lcccccc}
\hline \hline & $\begin{array}{c}\text { Ridge } \\
\text { width } \\
\text { Substrate }\end{array}$ & $\begin{array}{c}\text { Groove } \\
\text { width } \\
\text { (a) } \mu \mathrm{m}\end{array}$ & $\begin{array}{c}\text { Groove } \\
\text { depth } \\
\text { (d) } \mu \mathrm{m}\end{array}$ & $\begin{array}{c}\text { Pitch } \\
(\mathrm{a}+\mathrm{b}) \\
\mu \mathrm{m}\end{array}$ & $\begin{array}{c}\text { Aspect } \\
\text { ratio } \\
\text { (d/b) }\end{array}$ & $\begin{array}{c}\text { Space } \\
\text { ratio } \\
\text { (b/a) }\end{array}$ \\
\hline A & 5 & 5 & 2 & 10 & $1: 2.5$ & $1: 1$ \\
B & 5 & 10 & 2 & 15 & $1: 5$ & $2: 1$ \\
C & 5 & 15 & 2 & 20 & $1: 7.5$ & $3: 1$ \\
D & 5 & 20 & 2 & 25 & $1: 10$ & $4: 1$ \\
\hline \hline
\end{tabular}

and the space ratio (groove width to ridge width) varies from $1: 2.5$ to $1: 10$ and $1: 1$ to $4: 1$, respectively. In addition, in order to produce reliable statistic data, each grooved pattern is fabricated on an area of $1.05 \mathrm{~cm} \times 1.05 \mathrm{~cm}$, which has the capability of hosting a total of $2.5 \times 10^{5}$ human fetal osteoblast cells.

Both Wenzel and Cassie states ${ }^{20,21}$ are commonly used to address the relationship between the macroscopic surface roughness (here, geometric dimensions of grooves) and the contact angle of a water droplet, as shown in Fig. $3 .^{22}$ In the Wenzel state, a water droplet completely fills the grooves and eventually comes into contact with the bottom of the grooves, and its contact angle is described as

$$
\cos \theta_{w}=r_{w} \cos \theta_{0}
$$

where $r_{w}$ is the ratio of the actual wetted surface area to the planar surface area, $\theta_{0}$ is the intrinsic contact angle on a smooth surface and $\theta_{w}$ is the contact angle in the Wenzel state. In the groove geometry, $r_{w}$ is defined as ${ }^{4}$

$$
r_{w}=1+\frac{d}{a+b}
$$

However, in the Cassie model, a water droplet sits on top of the grooves with air entrapped underneath the droplet. In this case, the contact angle is described as

$$
\cos \theta_{C}=f\left(\cos \theta_{0}+1\right)-1,
$$

where $f$ is the ratio of the actual wetted surface area to the planar surface area and $\theta_{C}$ is the contact angle in the Cassie model. In the given groove geometry, $f$ is defined as ${ }^{4}$

$$
f=\frac{a}{a+b}
$$
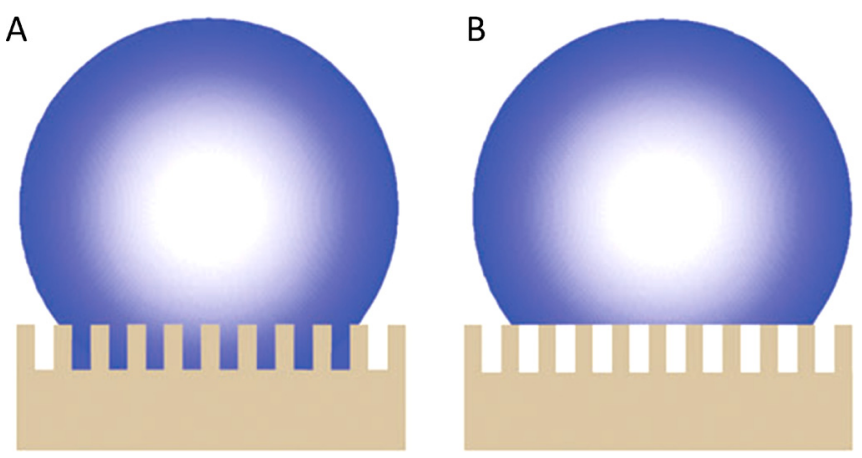

FIG. 3. Wetting behaviour of a water droplet on rough surfaces: (a) Wenzel model and (b) Cassie model. Reproduced with permission from Liu et al., Chem. Soc. Rev. 39(8), 3240 (2010). Copyright 2010 The Royal Society of Chemistry. 


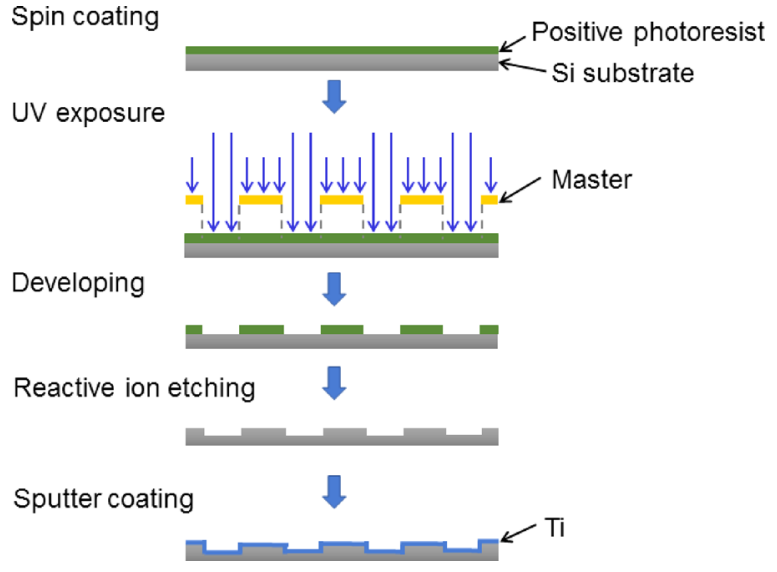

FIG. 4. Standard micro-processing steps for the fabrication of Ti-coated microgrooves on Si substrates.

\section{MATERIALS AND PATTERN FABRICATION}

Figure 4 shows the flow chart of the fabrication process of Ti-coated microgrooves on Si substrates, including photolithography, reactive ion etching (RIE), and sputter coating.

\section{A. Photolithography}

$\mathrm{Si}$ wafers of $100 \mathrm{~mm}$ in diameter (phosphatase/boron doping, $\langle 100\rangle$ orientation, $525 \pm 20 \mu \mathrm{m}$ thickness, Silicon Materials Inc.) were cleaned sequentially in acetone and isopropanol (IPA) in an ultrasonic bath for 3 min each. Subsequently,
TABLE II. Measured dimensions of fabricated Ti-coated microgrooves $(\mu \mathrm{m})$.

\begin{tabular}{lccc}
\hline \hline Substrate & Ridge width (a) & Groove width (b) & Groove depth (d) \\
\hline A & $5.06 \pm 0.12$ & $4.81 \pm 0.19$ & $2.26 \pm 0.19$ \\
B & $5.14 \pm 0.22$ & $9.60 \pm 0.27$ & $2.05 \pm 0.25$ \\
C & $5.07 \pm 0.13$ & $14.90 \pm 0.18$ & $2.10 \pm 0.24$ \\
D & $4.98 \pm 0.08$ & $19.43 \pm 0.22$ & $2.22 \pm 0.83$ \\
\hline \hline
\end{tabular}

they were rinsed with deionized (DI) water and dried with $\mathrm{N}_{2}$ gas, then dehydrated by baking at $120^{\circ} \mathrm{C}$ for $2 \mathrm{~min}$ and cooled down to room temperature. Next, they were spin-coated with the positive photoresist AZ1512HS (Merck Performance Materials $\mathrm{GmbH}$ ) for $45 \mathrm{~s}$ at $4000 \mathrm{rpm}$, followed by baking at $100^{\circ} \mathrm{C}$ for $50 \mathrm{~s}$ to give a $1.3-\mu \mathrm{m}$ thick layer, measured using a stylus profilometer (Dektak XT, Bruker). The photoresist layer was exposed to UV radiation in a Karl Suss MA6 mask aligner for 9s (exposure power: $12.22 \mathrm{~mW} / \mathrm{cm}^{2}$ ). The exposed resist layers were subsequently immersed in an AZ 726 metal ion free (MIF) developer for $10 \mathrm{~s}$. Finally, all substrates were hard baked on a hotplate at $100^{\circ} \mathrm{C}$ for $50 \mathrm{~s}$.

\section{B. Reactive ion etching (RIE) and sputter-coating}

In order to completely remove the photoresist residue, a descum recipe of using oxygen plasma to blast the substrate for $10 \mathrm{~s}$ was performed in a Bostch etching system (PlasmaPro 100 Estrelas Deep Silicon Etch System, Oxford). Then the patterns on the photoresist were transferred to the underlying $\mathrm{Si}$
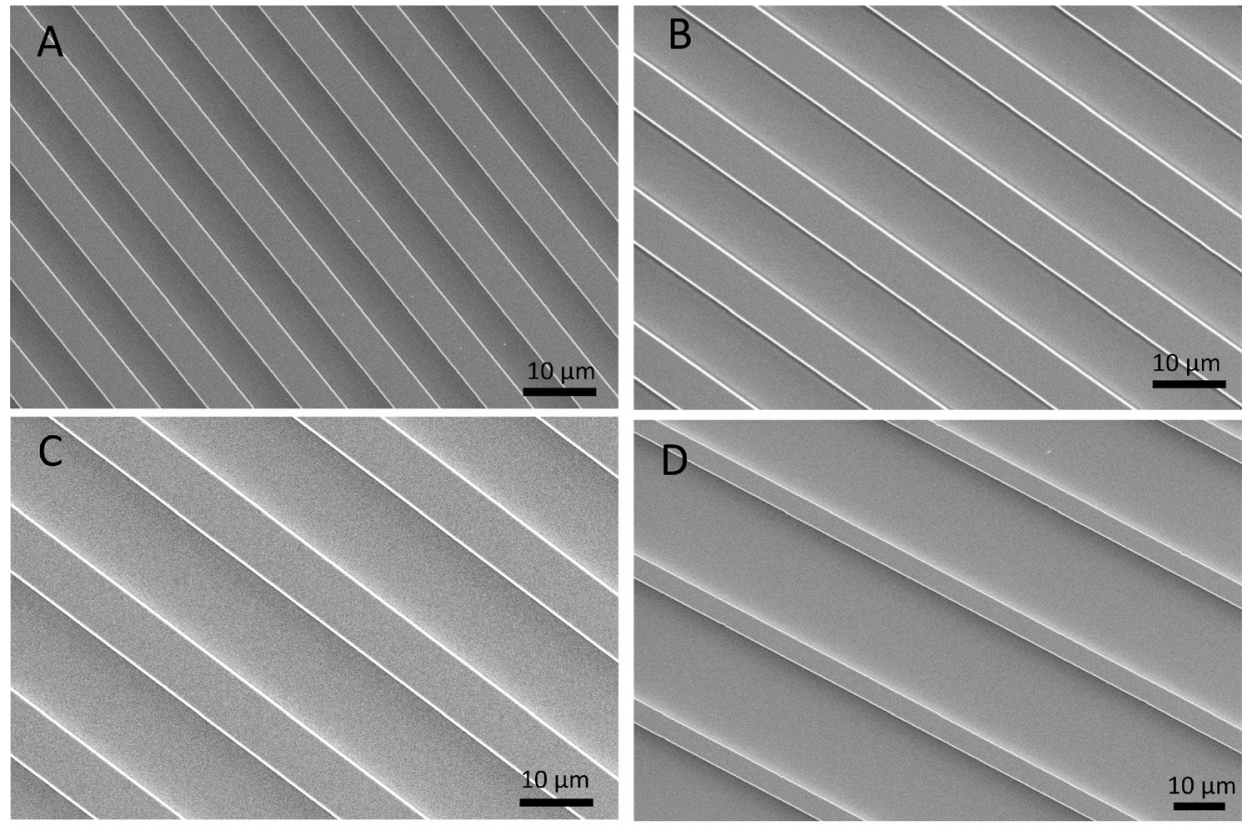

FIG. 5. SEM micrographs of Ti-coated grooves on Si substrates. (a) Substrate A, (b) Substrate B, (c) Substrate C, (d) Substrate D, and (e) cross-sections of Substrate A.

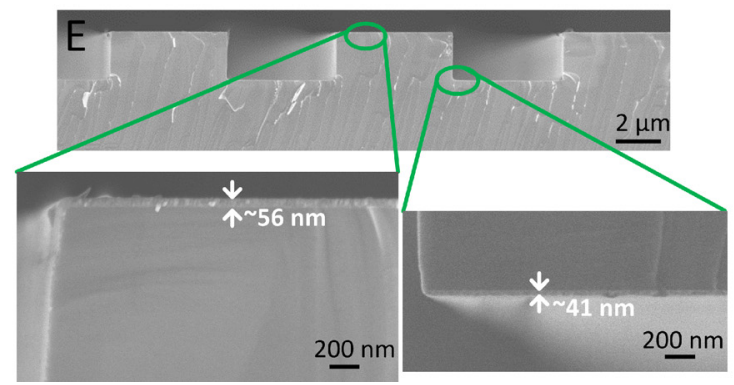



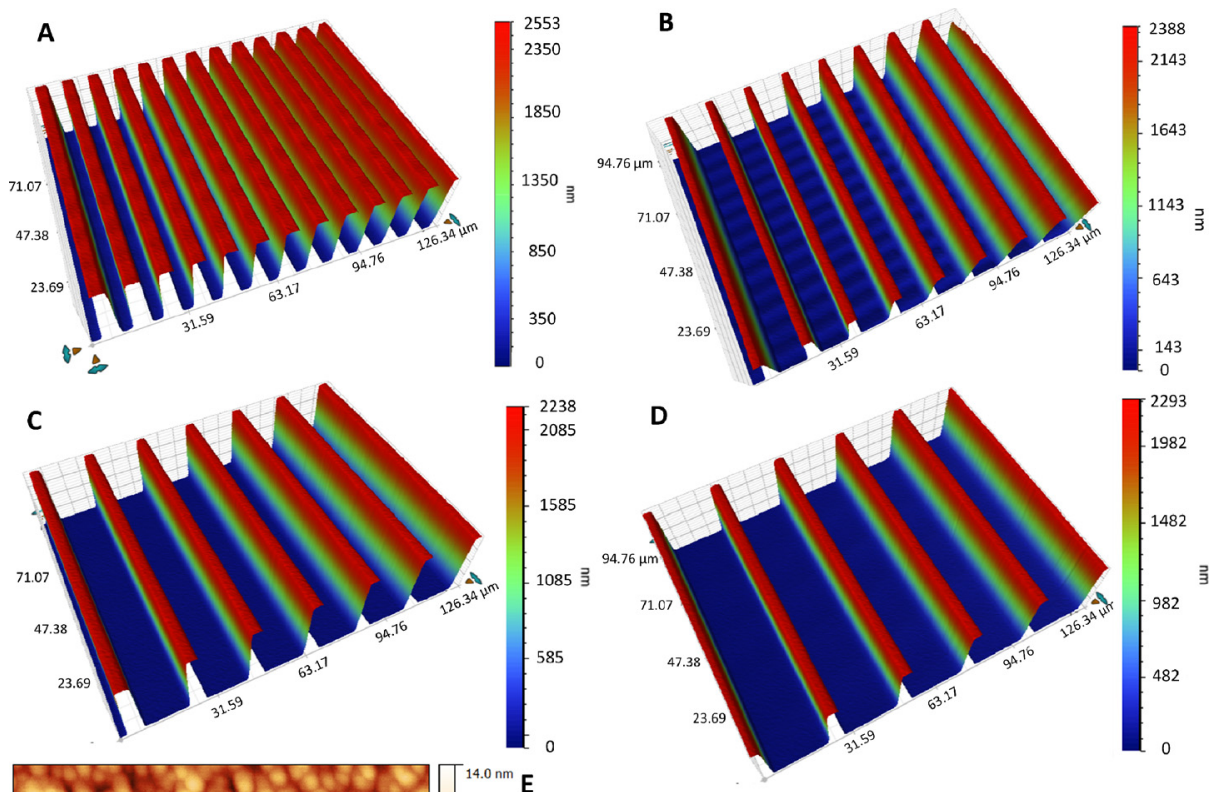

FIG. 6. 3D images for Ti-coated grooves using a light interferometer. (a) Substrate A, (b) Substrate B, (c) Substrate C, (d) Substrate D, (e) AFM analysis on the groove surfaces of Substrate A and its corresponding surface height profile plotted along the black line, and (f) AFM analysis on the ridge surfaces of Substrate A and its corresponding surface height profile plotted along the black line.
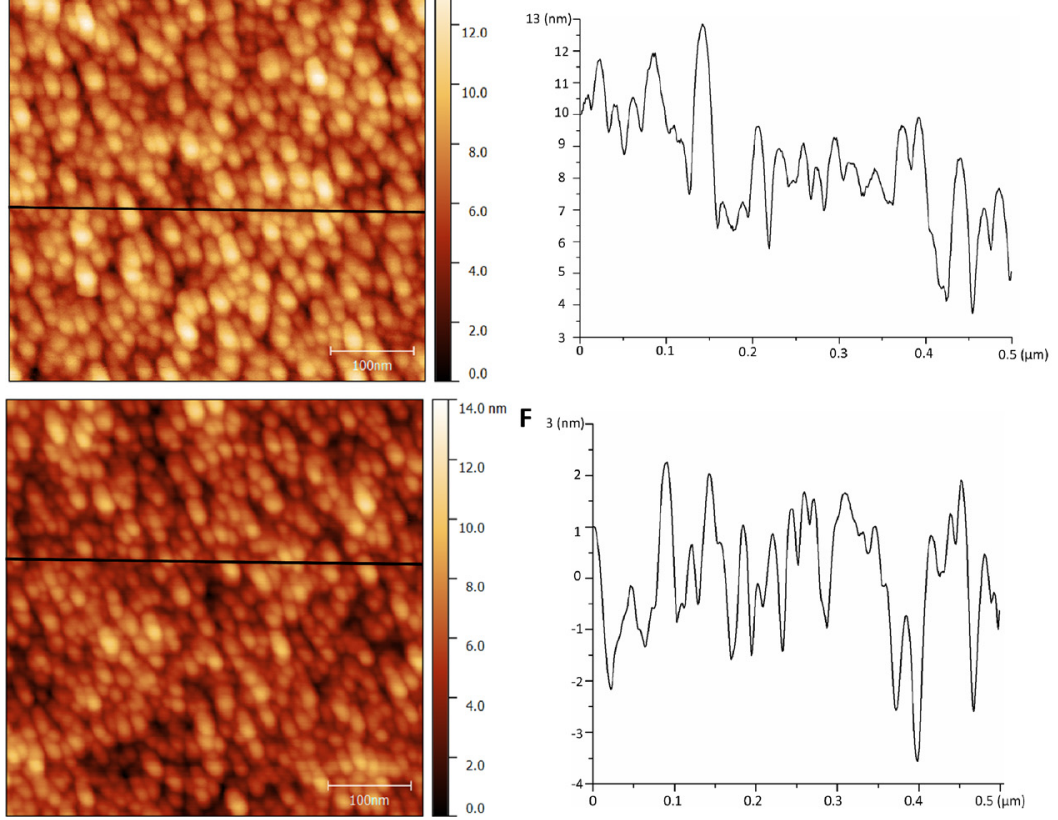

substrates by running a $\mathrm{Si}$ deep reactive ion etching (DRIE) recipe. Experimental parameters included the use of $\mathrm{SF}_{6}$ and $\mathrm{C}_{4} \mathrm{~F}_{8}$ ionized gases, respectively, at $35 \mathrm{sccm}$ and $40 \mathrm{sccm}, 25 \mathrm{~W}$ high frequency (HF) forward power, $650 \mathrm{~W}$ integrated-coupled-plasma (ICP) forward power, and helium (He) backing pressure at 10 Torr. This set of parameters produced grooves with a depth of $\sim 2 \mu \mathrm{m}$ into the Si substrates. After DRIE, the remaining photoresist on the substrate was stripped using oxygen plasma for $80 \mathrm{~s}$.

To improve the biocompatibility of the microgrooved surface, both microgrooved and blank $\mathrm{Si}$ wafers were sputter-coated with a $40-\mathrm{nm}$ thin Ti film. The coating was realised using radio frequency (RF) magnetron sputtering from a metallic Ti target (pressure of $5 \times 10^{-3}$ Torr, RF power of $200 \mathrm{~W}$, Ar atmosphere, and room temperature).

\section{Surface characterisation}

Surface morphology was analysed using an ultra-highresolution scanning electron microscope (SEM, Verios
460L, FEI). SEM imaging was acquired at an accelerating voltage of $5 \mathrm{kV}$ and a beam current of $25 \mathrm{pA}$. The true dimensions of each designed groove were measured from three replicates. To evaluate the cross-sections of the microgrooves as well as the quality of the Ti coating on the grooves, substrates were cleaved to allow cross-sectional SEM imaging. A white light interferometer (ContourGT, Bruker) was used to characterise the three-dimensional (3D) surface morphology and surface roughness including the average roughness $\left(\mathrm{S}_{\mathrm{a}}\right)$, the root mean square roughness $\left(\mathrm{S}_{\mathrm{q}}\right)$ and the maximum height of the surface $\left(S_{z}\right)$. To further analyse the roughness at the nanoscale of both the ridge and groove surfaces, atomic force microscopy (AFM, Bruker) was used in a tapping mode.

The static water contact angle $(\theta)$ was measured using a sessile-drop contact angle goniometer (Theta Lite Optical Tensiometer, ATA Scientific). The value of $\theta$ was measured at $5 \mathrm{~s}$ after placing Milli-Q water droplets $(2 \mu \mathrm{l})$ at three different areas on the substrate. All measurements were 


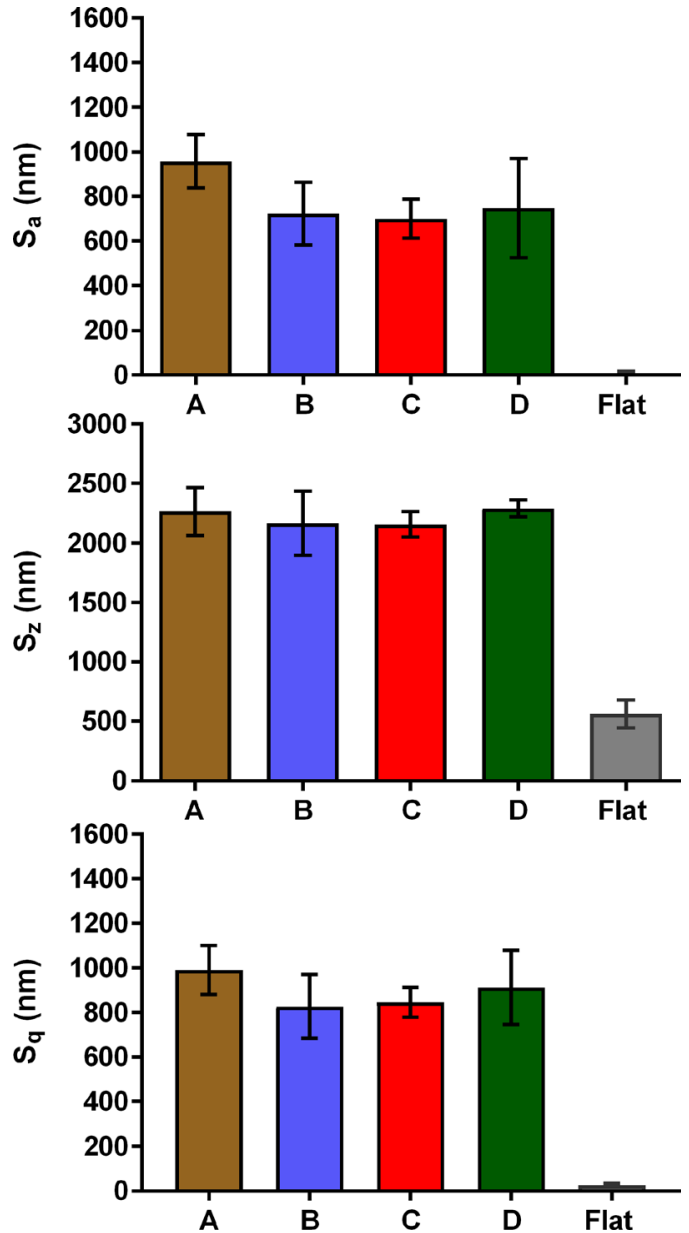

FIG. 7. Surface roughness values at the microscale of Ti-coated grooved and non-grooved flat surfaces. $\mathrm{S}_{\mathrm{a}}$ : the average roughness, $\mathrm{S}_{\mathrm{z}}$ : the maximum height of the surface, $\mathrm{S}_{\mathrm{q}}$ : the root mean square roughness.

performed under ambient conditions and repeated three times. The degree of anisotropy in wettability is defined as $\Delta \theta=\theta_{\perp}$ $-\theta_{/ /}$, where $\theta_{/ /}$and $\theta_{\perp}$ are contact angles measured along and perpendicular to the groove direction, respectively. . $^{3,4}$

\section{Cell culture and cell morphology analysis}

In vitro assessments were conducted on micro-grooved substrates using the human fetal osteoblast line (hFOB 1.19, ATCC, CRL-11372). The osteoblast cells were cultured in a mixture of Dulbecco's Modified Eagle's medium and Ham's F12 medium

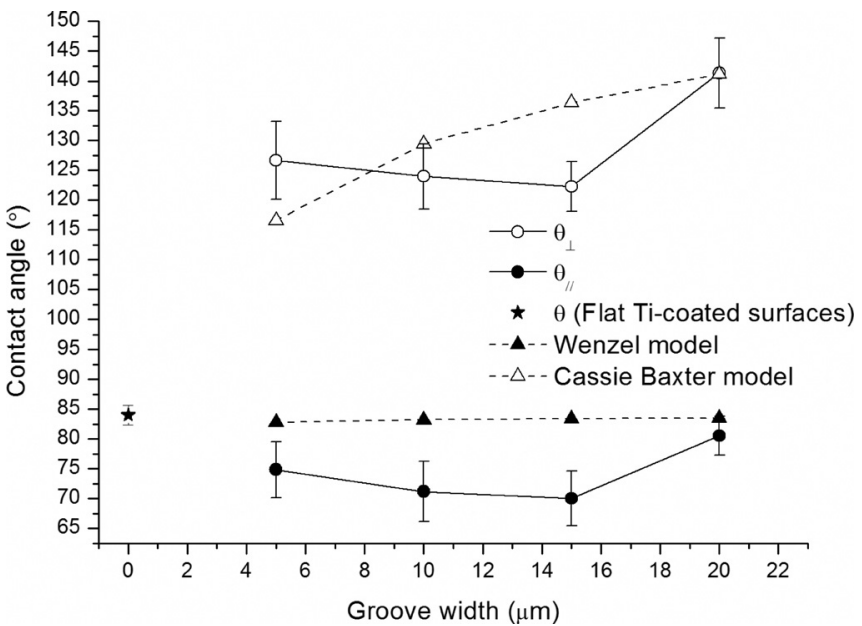

FIG. 9. Contact angles for the Ti-coated microgrooved and flat surfaces. Note that the Ti-coated flat surface has a contact angle of $84.0 \pm 1.6^{\circ}$.

(DMEM/F12, Thermo Fisher Scientific), supplemented with $10 \%$ (v/v) fetal bovine serum (Interpath Services) and $0.3 \mathrm{mg} / \mathrm{ml}$ Geneticin selective antibiotics G418 (Thermo Fisher Scientific). Cells were incubated at $34{ }^{\circ} \mathrm{C}$ in a humidified atmosphere that contains $5 \% \mathrm{CO}_{2}$. The entire medium was replaced every three days and confluent cells were passaged using TrypLE ${ }^{\mathrm{TM}}$ Express Enzyme (Invitrogen). Cells between the 4th and 7th passages were used in this study.

After culturing for three days, the cell-seeded substrates were transferred into new six-well plates and washed with sodium cacodylate. Then, the cells were fixed with $0.1 \mathrm{M}$ sodium cacodylate solution that contained $2 \%(\mathrm{v} / \mathrm{v})$ paraformaldehyde and $2.5 \%(\mathrm{v} / \mathrm{v})$ glutaraldehyde for $30 \mathrm{~min}$. Afterwards, all substrates were dehydrated through a graded series of ethanol $(30 \%, 50 \%, 70 \%, 90 \%, 95 \%$, and $100 \%)$. Finally, they were chemically dried with $100 \%$ hexamethyldisilizane (Sigma-Aldrich) for $20 \mathrm{~min}$. The dried substrates were sputter-coated with platinum $(\mathrm{Pt})$ prior to SEM analyses, which were performed at a voltage of $2 \mathrm{kV}$ and a beam current of $0.8 \mathrm{nA}$ (FEI, Verios 460L).

\section{RESULTS AND DISCUSSION}

\section{A. Surface morphology of grooved patterns}

Representative SEM micrographs of Ti-coated microgrooves of different groove widths are shown in Figs.
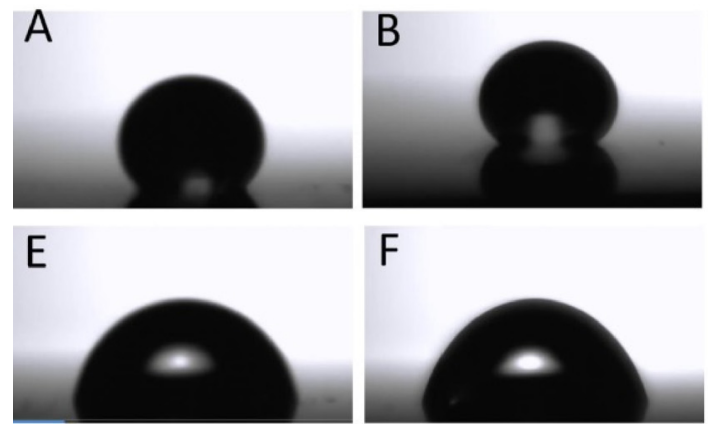
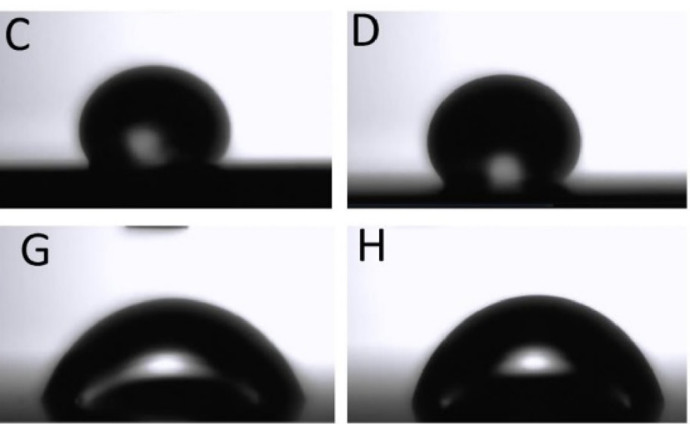

$\mathrm{H}$

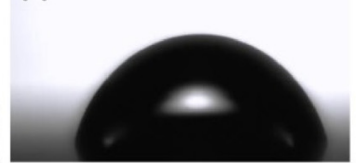

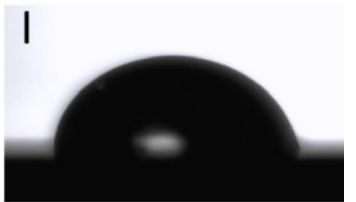

FIG. 8. Optical images of water droplets on four Ti-coated grooved surfaces and a non-grooved flat surface. Upper row: $\theta_{\perp}$ (perpendicular to grooves) and bottom row: $\theta_{/ /}$(parallel to grooves). (a) and (e) Substrate A, (b) and (f) Substrate B, (c) and (g) Substrate C and (d) and (h) Substrate D, and (i) a non-grooved flat surface. 
5(a)-5(d). Their cross-sectional views [Fig. 5(e)] revealed that these grooves are rectangular and their side walls are nearly perpendicular to the groove bottom $\left(\sim 92^{\circ}\right)$. The achieved parallel microgrooves shown in Fig. 5 are indicative of the high reliability of the micro-fabrication process employed. Table II summarises the measured dimensions of these grooves. The average thickness of the Ti coating on the ridge surface was $\sim 56 \mathrm{~nm}$, which was slightly higher than $41 \mathrm{~nm}$ measured on the groove bottom surface, but doubled that of $27 \mathrm{~nm}$ on the groove sidewall. This is acceptable as long as the entire surface is coated with Ti.

A 3D view of each grooved substrate is shown in Figs. 6(a)-6(d). According to 2D and 3D observations shown in Figs. 5 and 6, the grooved patterns achieved are consistent with our designs. The deviations from designed widths $(5-20 \mu \mathrm{m})$ mainly arise from the developing or exposure time of the photoresist, while the deviations from the designed depth $(2 \mu \mathrm{m})$ are mainly from the DRIE time. Figures 6(e) and 6(f) show AFM analyses of the ridge surfaces and groove bottom surfaces of Substrate A, respectively. The ridge and groove surfaces exhibited equivalent average $R_{a}$ values $(1.38 \pm 0.07$ for ridge and $1.59 \pm 0.08 \mathrm{~nm}$ for groove). Figure 7 compares the surface roughness measured for grooved surfaces and non-grooved flat substrate surfaces. The variations of $S_{a}$ (the average roughness), $S_{z}$ (the maximum height of the surface) and $\mathrm{S}_{\mathrm{q}}$ (the root mean square roughness) are limited to a small range for all four Ti-coated grooved surfaces, although the groove width varies significantly. This provides an important experimental basis for investigating the influence of surface grooves on wettability.

\section{B. Surface wettability}

Figure 8 shows a side view of the water droplets formed on both grooved surfaces and on a non-grooved flat surface. The latter exhibited isotropic water droplets which are essentially hemispherical. In contrast, droplets on the grooved surfaces were more elongated along the groove direction vs. its perpendicular direction. Figure 9 compares the measured $\theta_{/ /}$ and $\theta_{\perp}$ with the calculated contact angles using both Wenzel and Cassie models for all grooved surfaces. The non-grooved flat Ti-coated surface has a contact angle of $84.0 \pm 1.6^{\circ}$ [without Ti coating, the flat $\mathrm{Si}$ substrate has a contact angle of $38^{\circ}$ (Ref. 3)]. Overall, increasing groove width tends to increase wetting anisotropy. For example, $\theta_{\perp}$ decreased marginally from $126.7 \pm 6.5^{\circ}$ to $122.3 \pm 4.2^{\circ}$ with increasing groove width from 5 to $15 \mu \mathrm{m}$, but then increased sharply to $141.4 \pm 5.9^{\circ}$ with further increasing groove width to $20 \mu \mathrm{m}$ (Fig. 9). A similar trend was found for $\theta_{/ /}$as shown in Fig. 9. The measured $\theta_{/ /}$was close to that calculated from the Wenzel model, while $\theta_{\perp}$ were close to that predicted from the Cassie model. In other words, these models can be used to predict the degree of anisotropy in wettability on Ti-coated grooves. In particular, the wetting anisotropy $\left(\Delta \theta: \sim 60.8^{\circ}\right)$ was distinct for the grooved surfaces with a groove width of $20 \mu \mathrm{m}$, where the measured $\theta_{\perp}$ was very similar to the calculated contact angles using the Cassie model. Moreover, by increasing the groove width to $20 \mu \mathrm{m}$, the measured $\theta_{/ /}$gradually approached the contact angle of $84.0^{\circ}$ for the non-grooved flat surfaces.
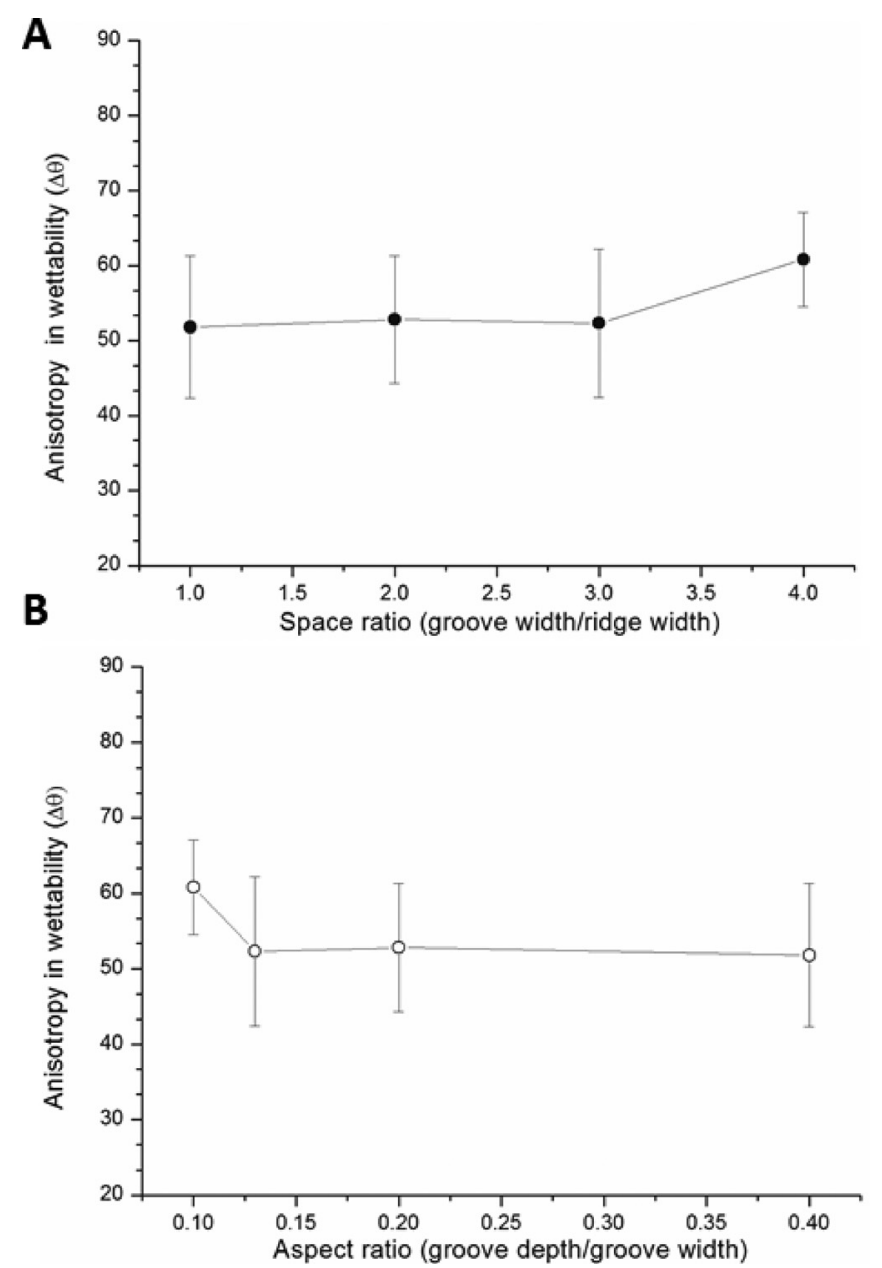

FIG. 10. The relationship between the space ratio (a), the aspect ratio (b) and the anisotropy in wettability of the Ti-coated microgrooved surfaces.

As surface chemistry (high purity $\mathrm{Ti}$ ) and surface roughness (Fig. 7) are similar for all grooved surfaces, it can be concluded that the observed anisotropic wettability is a result of anisotropic geometry of grooves. From Fig. 10(a), the anisotropy in wettability $(\Delta \theta)$ gradually increased from $51.8 \pm 9.5^{\circ}$ to $52.8 \pm 8.5^{\circ}$ with increasing space ratio from $1: 1$ to $2: 1$, and then increased to $60.8 \pm 6.3^{\circ}$ at the space ratio of $4: 1$. The opposite trend was observed for the anisotropy in wettability $(\Delta \theta)$ vs. the aspect ratio as shown in Fig. 10(b).

As proposed by Chung et al. and Xia and Brueck, anisotropic wettability was affected mainly by the anisotropic surface geometry. ${ }^{3,19}$ On the one hand, water droplets spread along the groove direction, and on the other hand, they were pinned at the groove edges in the direction perpendicular to the grooves. ${ }^{3,19}$ In other words, the three-phase contact line was continuous along the groove direction, but discontinuous in the direction perpendicular to the grooves. ${ }^{23} \mathrm{It}$ is easier for water droplets to spread along the groove direction as the energy barrier for spreading is usually much lower than in the direction perpendicular to the grooves. ${ }^{19,23}$ Chung et al. further suggested that the three-phase contact line can be more influential on anisotropic wettability than surface roughness. ${ }^{19}$

Based on the above observations and discussion, an effective way to enhance surface wettability is to minimise or avoid the discontinuity of the three-phase contact line of a 

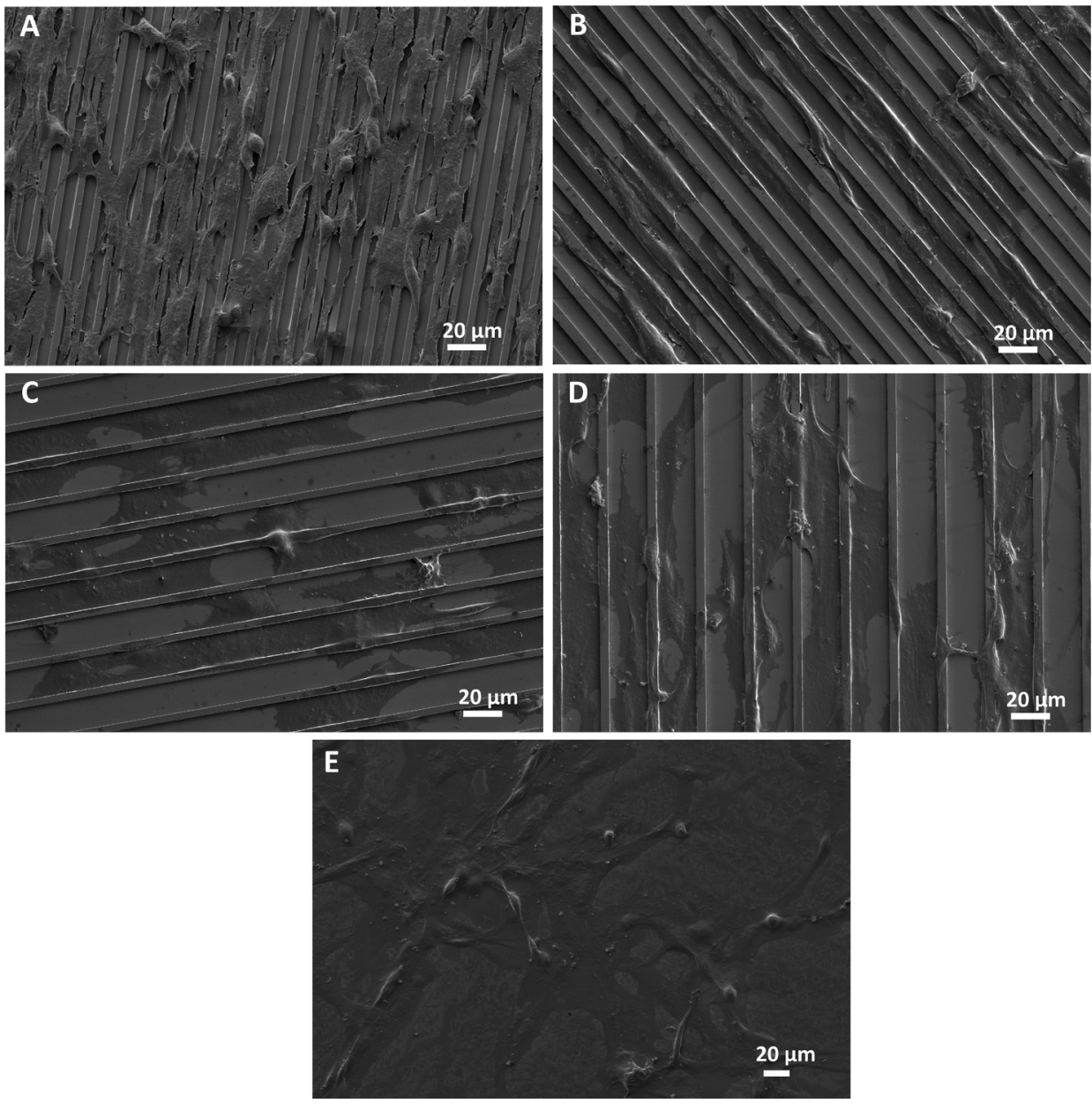

FIG. 11. SEM micrographs of osteoblasts cultured on grooved and nongrooved flat surfaces coated with $\mathrm{Ti}$ after culturing for 3 days. (a) Substrate A, (b) Substrate B, (c) Substrate C, (d) Substrate D, and (e) a flat substrate. water droplet in the direction perpendicular to grooves. ${ }^{3,5}$ In that regard, it is desirable to increase the ridge width and/or reduce the groove depth. ${ }^{5}$ For instance, it is challenging to achieve a deep penetration of a water droplet into narrow and deep grooves or those with high-aspect ratios, ${ }^{5,19}$ due to a substantial increase in the energy barrier for spreading with increasing groove depth. ${ }^{19}$ To cope up with such situations, the contact angle tends to increase and the water droplet finally reaches the Cassie state. ${ }^{19,24}$ In addition to the groove aspect ratio, the ridge slope (measured by $\alpha$ ) can also play an important role in influencing surface wettability by affecting the energy barrier for spreading. ${ }^{19}$ For instance, rectangular grooves (i.e., a $90^{\circ}$ slope) tended to hinder the spreading of a water droplet with air entrapped underneath. ${ }^{3}$ Decreasing the ridge slope can lead to increased surface wettability. ${ }^{5}$

Our results show that $\theta_{/ /}$is much smaller than $\theta_{\perp}$ for all fabricated grooves, which is consistent with the above discussion. For grooved patterns with a fixed ridge width and groove depth, increasing the groove width from 5 to $20 \mu \mathrm{m}$ means a reduction of the aspect ratio $(1: 2.5$ to $1: 10)$, but an increase of the space ratio (1:1 to $4: 1)$. This leads to an increase in the discontinuity of the three-phase contact line. Therefore, the contact angle in the direction perpendicular to grooves was close to that calculated using the Cassie model. On the other hand, the calculated free energy profile in the direction perpendicular to grooves displayed various high-energy metastable states, while the energy profile in the direction parallel to grooves and for non-grooved flat surfaces exhibited a minimum global free energy. ${ }^{8,19}$ This further suggests that water droplets that spread along the groove direction and on non-grooved flat surfaces are in a stable low-energy state, i.e., the Wenzel state. ${ }^{19,25}$ Consequently, the measured contact angle along the groove direction was close to that calculated using the Wenzel model (Fig. 9).

\section{The influence of anisotropic wettability on osteoblast morphology}

The SEM micrographs shown in Fig. 11 revealed significant differences in cell alignment and morphology between microgrooved and non-grooved flat surfaces. The osteoblasts spread randomly on the flat surfaces in polygonal shapes. In contrast, cells became elongated along the groove direction on all microgrooved surfaces. Moreover, cells tended to conform to the entire groove width as a result of the contact guidance by grooves.

It is generally accepted that a hydrophilic $\left(\theta<90^{\circ}\right)$ surface is in favour of cell spreading, differentiation and protein adsorption compared with a hydrophobic $\left(\theta>90^{\circ}\right)$ surface. ${ }^{26-29}$ Under in vitro conditions, osteoblasts tend to align and migrate along the groove direction. ${ }^{30,31}$ As mentioned earlier, cells behave similarly as viscous liquids do in the initial stage of spreading so that the low energy barrier allows the ease of cell spreading along the groove direction. This 
differs from the scenario of cell spreading along the direction perpendicular to the grooves, where cell spreading was largely restrained within one or two microgrooves, especially for narrow grooves (e.g., Substrate A). These observations are informative for the design of Ti bone implant surfaces when anisotropy in wettability is critically considered. However, more experimental data on in vitro and in vivo studies are needed to further clarify the detailed influence of each groove parameter on osteoblast responses.

\section{CONCLUSIONS}

This study has investigated the effect of groove geometry on anisotropic wettability. Ti-coated microgrooves with groove widths ranging from $5 \mu \mathrm{m}$ to $20 \mu \mathrm{m}$ at a constant ridge width of $5 \mu \mathrm{m}$ and a fixed depth of $2 \mu \mathrm{m}$ were successfully fabricated and characterised. Wettability experiments with water droplets revealed that the Ti-coated surface grooves exhibited significant anisotropy in wettability. On average, the contact angle measured parallel to the groove direction $\left(\theta_{/ /}\right)$was about $50^{\circ}-60^{\circ}$ smaller than that measured perpendicular to the groove direction $\left(\theta_{\perp}\right)$. The degree of anisotropy increased with increasing groove width. The Wenzel model can be used to predict the water contact angle along Ti-coated surface grooves, while the Cassie Model was used to predict the contact angle perpendicular to the grooves. Together, they can reasonably predict anisotropy in wettability of Ti-coated grooves. The anisotropy of wettability can significantly affect in vitro cell responses, where cells tend to spread preferentially along the microgrooves. The experimental findings of this study provide first-hand information for understanding the effect of Ti surface grooves on anisotropic wettability for various applications, including orthopaedic Ti implants.

\section{ACKNOWLEDGMENTS}

This work was supported in part by the Australian Research Council (ARC) through Grant Nos. LP140100607 and DP140100702. Xi'an Sailong Metal Materials Co., Ltd. (Xi'an, China) and Anatomics Pty Ltd (Melbourne, Australia) are industry partners of the ARC LP140100607. N. Gui acknowledges the support from the China Scholarship Council (CSC). Mr. Taimur Ahmed from the School of Engineering, RMIT University is thanked for significant assistance in performing sputter coating of the substrates. The authors acknowledge the facilities and scientific assistance from the Australian Microscopy \& Microanalysis Research Facility at RMIT Microscopy \& Microanalysis Facility and RMIT Micro Nano Research Facility.
${ }^{1}$ I. Polmear, D. StJohn, J.-F. Nie, and M. Qian, Light Alloys: Metallurgy of Light Metals, 5th ed. (Butterworth-Heinemann, Waltham, Massachusetts, 2017), p. 369.

${ }^{2}$ H. P. Tang, J. Wang, and M. Qian, Titanium Powder Metallurgy: Science, Technology and Applications (Butterworth-Heinemann, Waltham, Massachusetts, 2015), p. 533.

${ }^{3}$ D. Xia and S. R. J. Brueck, Nano Lett. 8(9), 2819 (2008).

${ }^{4}$ C. Ma, S. Bai, X. Peng, and Y. Meng, Appl. Surf. Sci. 284(Suppl. C), 930 (2013).

${ }^{5}$ L. Liping, M. J. Anthony, and C. Dmitri, J. Micromech. Microeng. 19(3), 035026 (2009).

${ }^{6}$ M.-H. Lee, N. Oh, S.-W. Lee, R. Leesungbok, S.-E. Kim et al., Biomaterials 31(14), 3804 (2010).

${ }^{7}$ E. H. Ahn, Y. Kim, Kshitiz, S. S. An, J. Afzal et al., Biomaterials 35(8), 2401 (2014).

${ }^{8}$ Y. Ding, J. Sun, H. W. Ro, Z. Wang, J. Zhou et al., Adv. Mater. 23(3), 421 (2011).

${ }^{9}$ D. Xia, X. He, Y.-B. Jiang, G. P. Lopez, and S. R. J. Brueck, Langmuir 26(4), 2700 (2010).

${ }^{10}$ W. Lee, M.-K. Jin, W.-C. Yoo, and J.-K. Lee, Langmuir 20(18), 7665 (2004).

${ }^{11}$ N. Takeshita, L. A. Paradis, D. Öner, T. J. McCarthy, and W. Chen, Langmuir 20(19), 8131 (2004).

${ }^{12}$ D. S. Andrew and M. J. Anthony, J. Micromech. Microeng. 16(8), 1571 (2006).

${ }^{13}$ C. Tamiello, A. B. Buskermolen, F. P. Baaijens, J. L. Broers, and C. V. Bouten, Cell. Mol. Bioeng. 9(1), 12 (2016).

${ }^{14}$ R. A. Gittens, R. Olivares-Navarrete, Z. Schwartz, and B. D. Boyan, Acta Biomater. 10(8), 3363 (2014).

${ }^{15} \mathrm{X}$. Lu and Y. Leng, J. Biomed. Mater. Res., Part A 66(3), 677 (2003).

${ }^{16}$ D. Kabaso, E. Gongadze, S̆. Perutková, C. Matschegewski, V. KraljIglič et al., Comput. Methods Biomech. Biomed. Eng. 14(05), 469 (2011).

${ }^{17}$ A. Azeem, A. English, P. Kumar, A. Satyam, M. Biggs et al., Nanomedicine 10(5), 693 (2015).

${ }^{18}$ S.-P. Yang and T.-M. Lee, J. Mater. Sci.: Mater. Med. 22(4), 1027 (2011).

${ }^{19}$ J. Y. Chung, J. P. Youngblood, and C. M. Stafford, Soft Matter 3(9), 1163 (2007).

${ }^{20}$ R. N. Wenzel, Ind. Eng. Chem. 28(8), 988 (1936).

${ }^{21}$ A. Cassie and S. Baxter, Trans. Faraday Soc. 40, 546 (1944).

${ }^{22}$ K. Liu, X. Yao, and L. Jiang, Chem. Soc. Rev. 39(8), 3240 (2010).

${ }^{23}$ Z. Yoshimitsu, A. Nakajima, T. Watanabe, and K. Hashimoto, Langmuir 18(15), 5818 (2002).

${ }^{24}$ E. Martines, K. Seunarine, H. Morgan, N. Gadegaard, C. D. Wilkinson et al., Nano Lett. 5(10), 2097 (2005).

${ }^{25}$ G. Pashos, G. Kokkoris, and A. G. Boudouvis, Langmuir 31(10), 3059 (2015).

${ }^{26}$ N. Gui, W. Xu, D. Myers, R. Shukla, H. Tang et al., Biomater. Sci. 6(2), 250 (2018).

${ }^{27}$ J. Y. Lim, A. F. Taylor, Z. Li, E. A. Vogler, and H. J. Donahue, Tissue Eng. 11(1-2), 19 (2005).

${ }^{28}$ G. Zhao, Z. Schwartz, M. Wieland, F. Rupp, J. Geis-Gerstorfer et al., J. Biomed. Mater. Res., Part A 74(1), 49 (2005).

${ }^{29}$ J. Wei, T. Igarashi, N. Okumori, T. Igarashi, T. Maetani et al., Biomed. Mater. 4(4), 045002 (2009).

${ }^{30}$ A. Calzado-Martín, A. Méndez-Vilas, M. Multigner, L. Saldana, J. L. González-Carrasco et al., Acta Biomater. 7(4), 1890 (2011).

${ }^{31}$ C. J. Bettinger, R. Langer, and J. T. Borenstein, Angew. Chem., Int. Ed. 48(30), 5406 (2009). 